\title{
REVIEW
}

Open Access

\section{What causes failure of fixed orthodontic retention? - systematic review and meta- analysis of clinical studies}

\author{
Maciej Jedliński ${ }^{1 *}$ D, Katarzyna Grocholewicz', Marta Mazur ${ }^{2}$ and Joanna Janiszewska-Olszowska'
}

\begin{abstract}
Background: Orthodontic retention aims to maintain optimal teeth positions after active treatment. The stability is affected by numerous factors, including patients' individual features, thus retention should be adjusted in the most optimal way. Bonding a retainer makes retention less dependent on patient's compliance.

Questions arise: What wire or fiber splint type provides the best treatment stability? What materials should be used to bond the wire or fiber splint? Should be the bonding procedure be direct or indirect? The aim of the study is to assess and synthesize available controlled trials investigating failures of fixed retainers.

Methods: Literature searches of free text and MeSH terms were performed in Scopus, Web of Science, Embase and PubMed Central in order to find studies, referring to failures of fixed retention (12th February 2021). The keywords were: ("orthodontic retainers AND failure AND wire"). The framework of this systematic review according to PICO was: Population: orthodontic patients; Intervention: fixed orthodontic retainer bonding; Comparison: Different protocols of fixed orthodontic retention applied; Outcomes: failure rate, survival rate. Three different specific scales from the Cochrane Collaboration Handbook were used, according to each study type. Additionally, a meta-analysis was conducted to compare the effectiveness of retention using fiber reinforced composite and multistranded steel wire.

Results: The search identified 177 potential articles: 114 from PubMed, 41 from Scopus, 20 from Web of Science and 2 from Embase. After excluding studies inconsistent with selection criteria, 21 studies were included and subjected to qualitative analysis. The main outcome investigated was failure rate. This systematic review has some potential limitations due to the heterogeneity of design between included studies.

Conclusions: No retainer is proved to guarantee a perfect stability of dental alignment. The retainer should be bonded to all adherent teeth, preferably with additional use of bonding resin. No wire or fiber splint present superior characteristics concerning failure rate. Fiber reinforced composite retention is more sensitive to operator skills, and with imperfect bonding technique, failure rate is much higher. During the first 6 months after bonding retainer the patient should be under frequent control. The study protocol was registered in PROSPERO database with the number CRD42021233406.
\end{abstract}

Keywords: Fixed retainer, Fiber splint, Breakage, Debonding, Relapse

\footnotetext{
*Correspondence: maciej.jedlinski@pum.edu.pl

${ }^{1}$ Department of Interdisciplinary Dentistry, Pomeranian Medical University in Szczecin, 70-111 Szczecin, Poland

Full list of author information is available at the end of the article
}

\section{$\triangle B M C$}

(c) The Author(s). 2021 Open Access This article is licensed under a Creative Commons Attribution 4.0 International License, which permits use, sharing, adaptation, distribution and reproduction in any medium or format, as long as you give appropriate credit to the original author(s) and the source, provide a link to the Creative Commons licence, and indicate if changes were made. The images or other third party material in this article are included in the article's Creative Commons licence, unless indicated otherwise in a credit line to the material. If material is not included in the article's Creative Commons licence and your intended use is not permitted by statutory regulation or exceeds the permitted use, you will need to obtain permission directly from the copyright holder. To view a copy of this licence, visit http://creativecommons.org/licenses/by/4.0/ The Creative Commons Public Domain Dedication waiver (http://creativecommons.org/publicdomain/zero/1.0/) applies to the data made available in this article, unless otherwise stated in a credit line to the data. 


\section{Background}

Orthodontic retention is defined as maintaining optimal aesthetic and functional teeth positions after cessation of active orthodontic treatment. It should be recognized as an integral phase of orthodontic treatment [1]. Two forms of retention can be distinguished: fixed - in the form of appliance attached to the lingual tooth surface, or removable- in the form of acrylic plates or transparent thermoformed splints [2].

The stability of orthodontic treatment is affected by numerous factors, including type of initial malocclusion, age, gender, pathology of the surrounding soft tissues, patient compliance and retention protocol applied [3]. A potential relapse may be due to: lasting remodeling periodontal tissues, muscular imbalance or changes produced by growth and ageing [4]. Tooth movement resulting from ageing occurs in all subjects, disregarding the positive or negative history of orthodontic treatment. Little et al. [5] in their long-term observational studies in 1988 found that 90\% of cases relapse within 10-20 years after the end of retention. The tendency to relapse or post-treatment undesired tooth movement varies in individual cases [4].

Since orthodontists have no influence on the patient's individual features, the protocol of retention phase should be adjusted in the most optimal way. The results of the latest survey studies have shown that European orthodontists are much more willing to use permanent retention devices, especially in the area of lower anterior teeth $[6,7]$. The greatest approval of specialists enjoys retention carried out simultaneously with a removable retention device and a fixed retention device $[6,7]$.

Nowadays people pay a great attention to their appearance, thus the demand for esthetic orthodontic treatment is increasing. Patients place great emphasis on the stability of treatment results. Treatment involves not only physical but also emotional effort for patient $[8,9]$ thus a possible relapse causes dissatisfaction. For the best compliance, the patient should apply for regular appointments several times a year during retention phase [10]. A special information campaign "Hold that smile" was held by the British Orthodontic Society, to educate patients on the importance of the retention phase of orthodontic treatment, and enhance a better cooperation [11]. Nevertheless, the use of removable retainers always depends most on the patient's self-discipline, whereas the doctor's influence remains limited.

Bonding a fixed retainer makes retention less dependent on patient's compliance. Questions arise concerning the wire: What wire or fiber splint type provides the best treatment stability? What materials should be used to bond the wire or fiber splint to tooth surface? What should be the procedure of bonding fixed retention (direct or in-direct)? Since opinions on this subject vary, the authors have tried to systemize the current knowledge about bonding fixed retention in order to try to create clinical recommendations.

\section{Aim of the study}

The aim of the study was to assess and synthesize available controlled trials investigating the failures of fixed retainers.

\section{Materials and methods}

\section{Search strategy}

This systematic review was conducted according to the PRISMA statement [12], the PRISMA reporting guidelines $[13,14]$ and the guidelines from the Cochrane Handbook for Systematic Reviews of Interventions [15]. Literature searches of free text and $\mathrm{MeSH}$ terms were performed in Scopus, Web of Science, Embase and PubMed Central search engines in order to find studies, exploring the topic of bonding fixed retention in terms of failures (12th February 2021). All searching was performed using a combination of subject headings and free-text terms: the final search strategy was determined through several pre-searches. The keywords used in the search strategy were as follows: ("orthodontic retainers AND failure AND wire"). The study protocol was registered after the screening stage in PROSPERO database with the number CRD42021233406. The framework of this systematic review according to PICO [16] was: Population: orthodontic patients; Intervention: fixed orthodontic retainer bonding; Comparison: Different protocols of fixed orthodontic retention applied; Outcomes: failure rate, survival rate. The included articles discuss the choice of retention wire, the type of composite used for bonding, and try to answer why failure occurs when using fixed retention.

\section{Eligibility criteria}

The following inclusion criteria were applied for this systematic review:

Type of study: randomized clinical trials (RCTs), cohort studies, case - control studies (CCSs), retrospective studies on fixed retainers efficacy.

Results of the study: Fixed retention failure defined as debonding or undesired tooth movement.

Object of the study: a) comparison of the efficacy of wires or fiber glass splints bonded with same procedure and using the same material or b) comparison of efficacy of bonding materials with the same type of procedure and the same type of wire Subject of the study: human subjects

The following exclusion criteria were applied: incomplete studies, in-vitro studies, studies in which 
concurrent procedures were applied (as fibrotomy), lack of effective statistical analysis; papers not related to fixed retention failure, studies not written in English.

\section{Data extraction}

Titles and abstracts were independently selected by two authors (MJ and KG), following the inclusion criteria. The full text of each identified article was then analyzed to verify, whether it was suitable for inclusion. Whenever disagreement occurred, it has been resolved by discussion with the third author (JJ) by creating a spreadsheet in order to compare them through according to the Cochrane Collaboration guidelines [15]. Authorship, year of publication, type of each eligible study and its relevance regarding to the use of fixed orthodontic retention were extracted by one author (JJ) and examined by another author (MJ).

\section{Quality assessment}

According to the PRISMA statements the evaluation of methodological quality gives an indication of the strength of evidence provided by the study because methodological flaws can result in biases [12].

The quality assessment of RCTs was performed using the revised tool for assessing risk of bias in randomized trials (RoB 2) [17]. This tool assesses the possible risk of bias by evaluating five characteristics: sequence generation, allocation concealment, blinding to personnel, blinding to outcome analysis and incomplete outcome bias in accordance with the Cochrane guidelines. There are three possible grades for each characteristic: low RoB - meaning no bias, or if present, rather unlikely to alter the results significantly, some concerns - meaning risk of bias that raises some doubt about the results and high RoB - bias may alter the results significantly [18]. If other type of bias occurred, it has been described more specifically. What is more, the quality assessment of CCSs and retrospective studies was performed using Newcastle - Ottawa Scale for Case-control studies [19]. To perform the evaluation of eventual risk of bias in cohort studies the Newcastle-Ottawa Quality Assessment Form for Cohort Studies has been employed [20]. The quality assessment of all included studies in both scales of Newcastle-Ottawa Assessment forms is based on object selection, comparability and ensuring undisturbed overlap of processes leading to the outcome. The possible quality assessment score ranged from 0 to 9 points, with the higher score indicating the better quality of given study. For each characteristic evaluated, one point was given. The study could receive 4 points for the ideal object selection, 2 points for the ideal comparability and 3 points for the ideal determination of the exposure and its evaluation.

\section{Meta-analysis}

Meta-analysis was performed using random-effect model via metafor $\mathrm{R}$ package, [21] with LRR (Log Risk Ratio) and $95 \%$ confidence intervals $(95 \% \mathrm{CI}$ ) being calculated as effect estimates. LRR is relatively insensitive to differences in baseline risk [22]. Heterogeneity was assessed quantitatively using I2-statistics and Cochran's Q [23]. Publication bias was estimated using funnel plot.

\section{Results \\ Search results}

The search strategy identified 177 potential articles: 114 from PubMed Central, 41 from Scopus, 20 from Web of science and 2 from Embase. After removal of duplicates, 149 articles were analyzed. Subsequently, 112 papers were excluded because they did not meet the inclusion criteria. Of the remaining 26 papers, 5 were excluded because they were not relevant to the subject of the study. They focused mainly on other phenomena - such as influence of fixed retention on periodontal tissues or did not meet inclusion criteria, because of type of the study. The remaining 21 papers were included in the qualitative synthesis. Table 1 summarizes the characteristics of each of the included studies. Prisma 2020 Flow Diagram representing study selection process has been presented in Fig. 1.

\section{Quality assessment}

Due to the fact that three types of studies were qualified for the review, three different specific scales from the Cochrane Collaboration Handbook were used. The evaluation of RCTs is presented in Table 2 in a descriptive form, while the evaluation of the included CCs and cohort studies in numerical form, successively in Tables 3 and 4.

\section{Failures of fixed retainers}

The failure rates in studies included ranged from $7.3 \%$ in the study by Kocher et al. [43] to $50 \%$ in the study by Rose et al. 2002 [33]. Patients, who once had the retainer detach, are at risk of repeated failure. Retention failure occurs more frequently in the maxilla than in the mandible. Concerning bonding failures statistically significant differences concerning failure rates, discoloration and calculus accumulation [29] have been reported between retainers bonded with additional use of a bonding agent versus retainers bonded with a composite material only $[29,36]$. Adhesive failure (with no retained composite material on enamel surface) is the most common type of bond failure observed in fixed lingual retainers $[28,42]$ Concerning the stability of dental alignment, irregularity index increases with time despite the presence of bonded retainers $[25,27,41]$. No difference has been confirmed as far as type of wire and splint was concerned. Referring to composite material used for retainer 


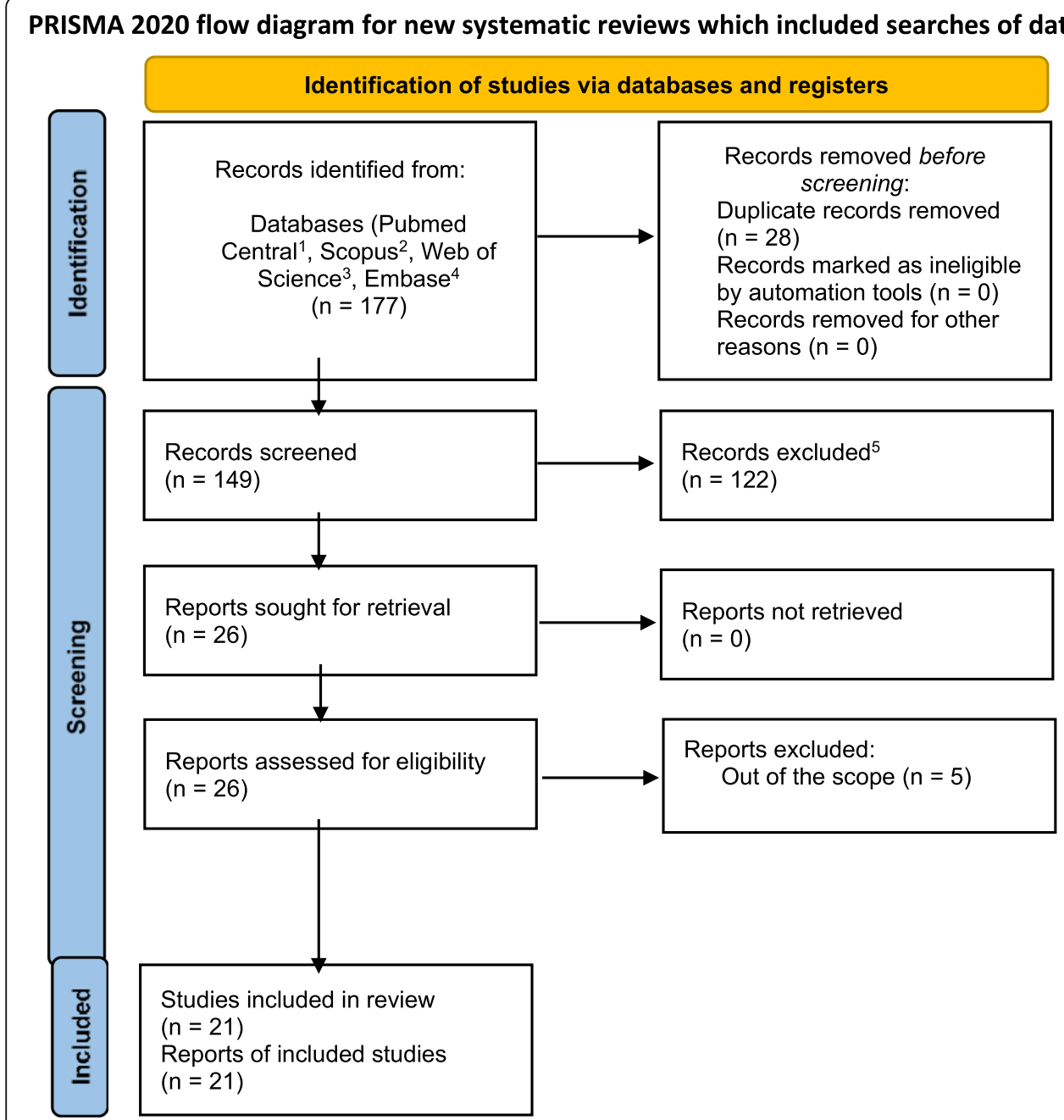

1 - search string: ("orthodontic retainers"[MeSH Terms] OR ("orthodontic"[All Fields] AND "retainers"[All Fields]) OR "orthodontic retainers"[All Fields]) AND failure[All Fields] AND ("bone wires"[MeSH Terms] OR ("bone"[All Fields] AND "wires"[All Fields]) OR "bone wires"[All Fields] OR "wire"[All Fields])

2 - search string: TITLE-ABS-KEY ("orthodontic retainers" AND "failure" AND "wire" ) AND ( LIMIT-TO ( SUBJAREA, "DENT" ))

3 - search string: ALL FIELDS: ("orthodontic retainers" AND "failure" AND "wire")

WEB OF SCIENCE CATEGORIES: ( DENTISTRY ORAL SURGERY MEDICINE )

4 - search string: ('orthodontic retainers'/exp OR 'orthodontic retainers') AND ('failure'/exp OR 'failure') AND ('wire'/exp OR 'wire')

AND [embase]/lim NOT ([embase]/lim AND [medline]/lim)

5 - because not relevant to the subject; author's debates; incomplete studies, in-vitro studies, studies in which auxiliary processes were applied, lack of effective statistical analysis; papers not related to fixed retention failure, studies not written in English.; case reports, reviews.

Fig. 1 Prisma 2020 Flow Diagram representing study selection process

bonding, one study has been included proving less failures with Transbond XT versus Filtek Supreme XTE (flowable) [36]. It must be noted, that retainers bonded to the surface of all adherent teeth were superior concerning stability of alignment to retainers bonded to two marginal teeth only [27].

The novelty - customized CAD/CAM (computer-aided design/computer-aided manufacture) nitinol retainer 


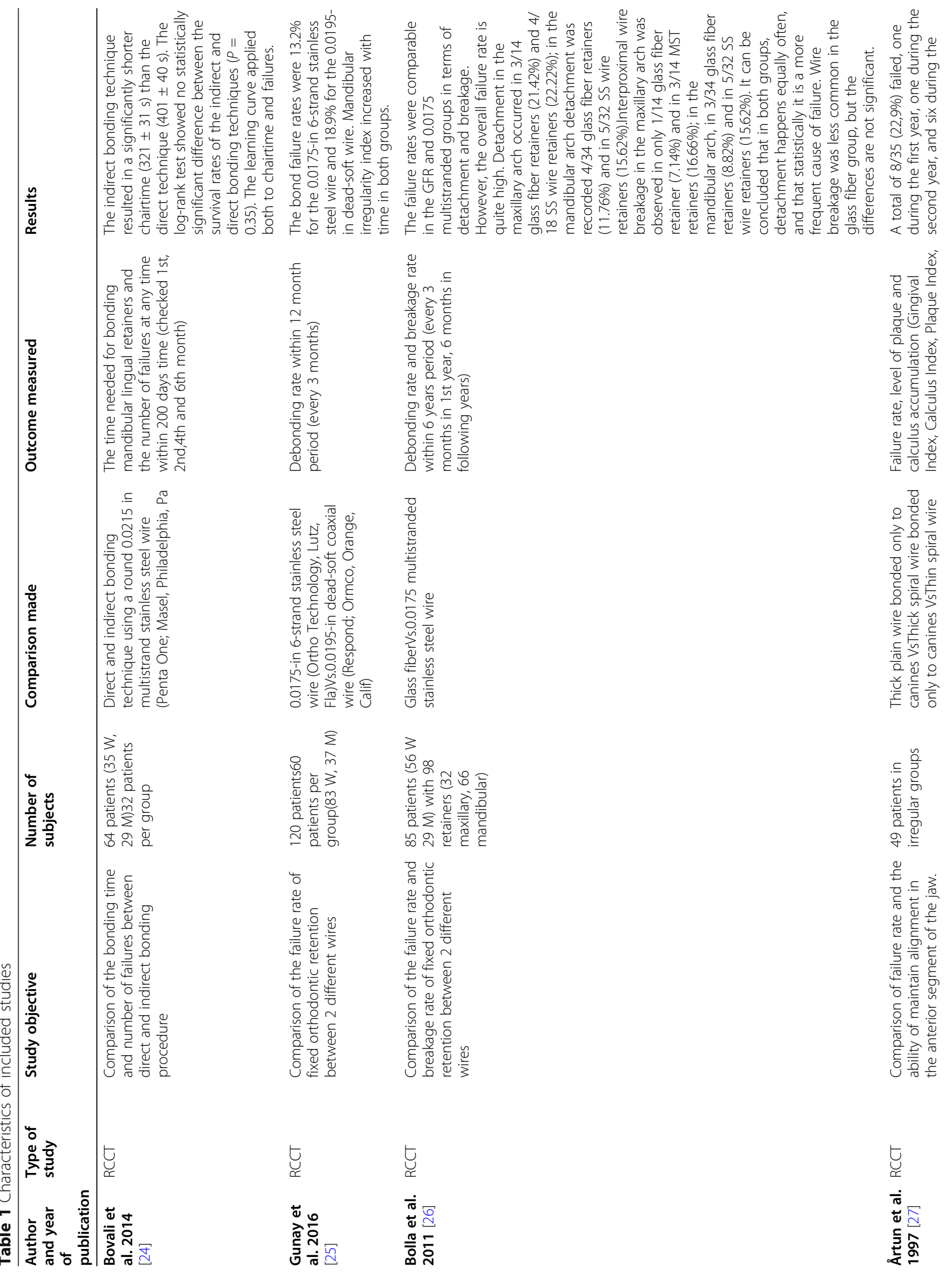




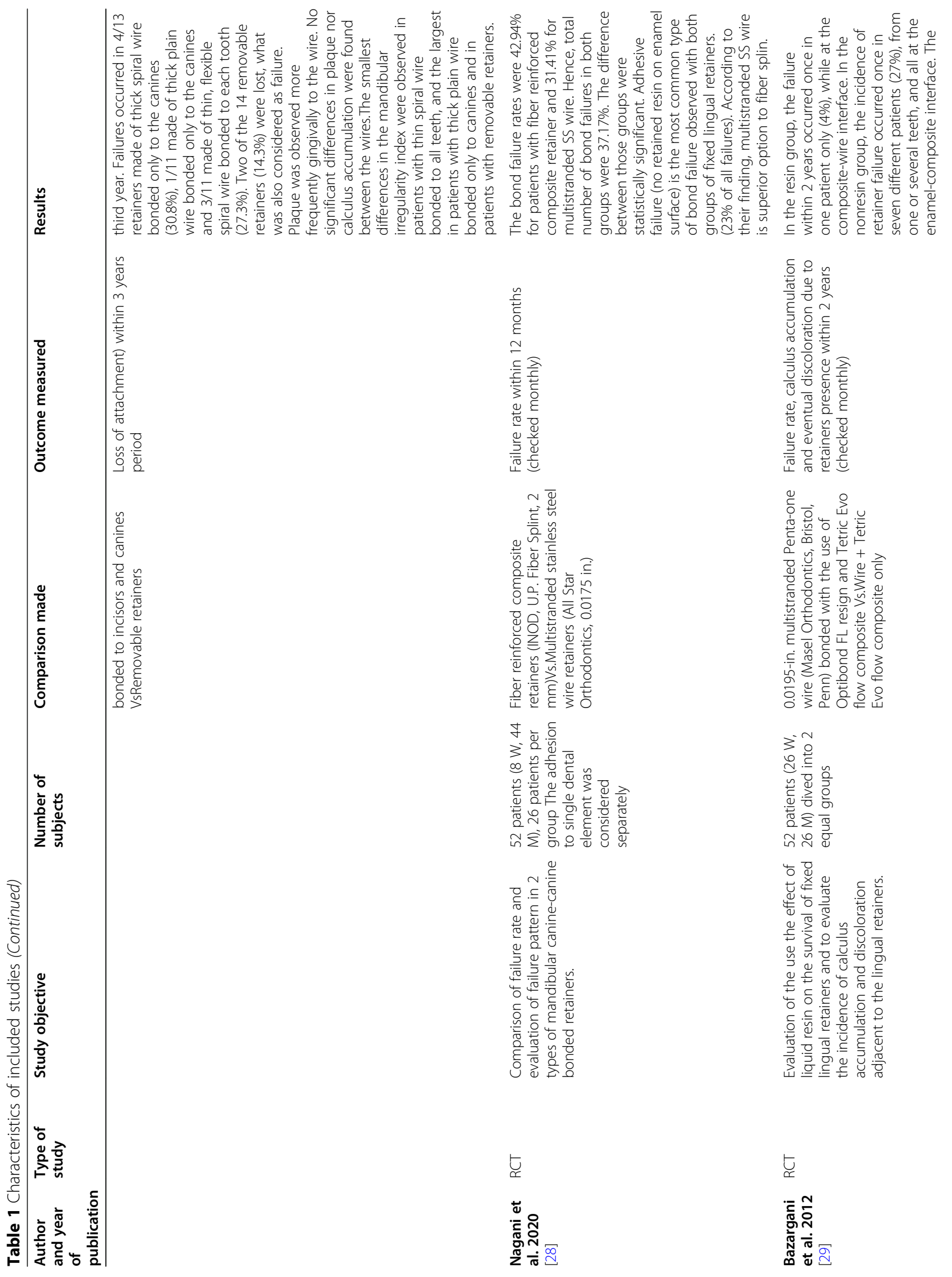




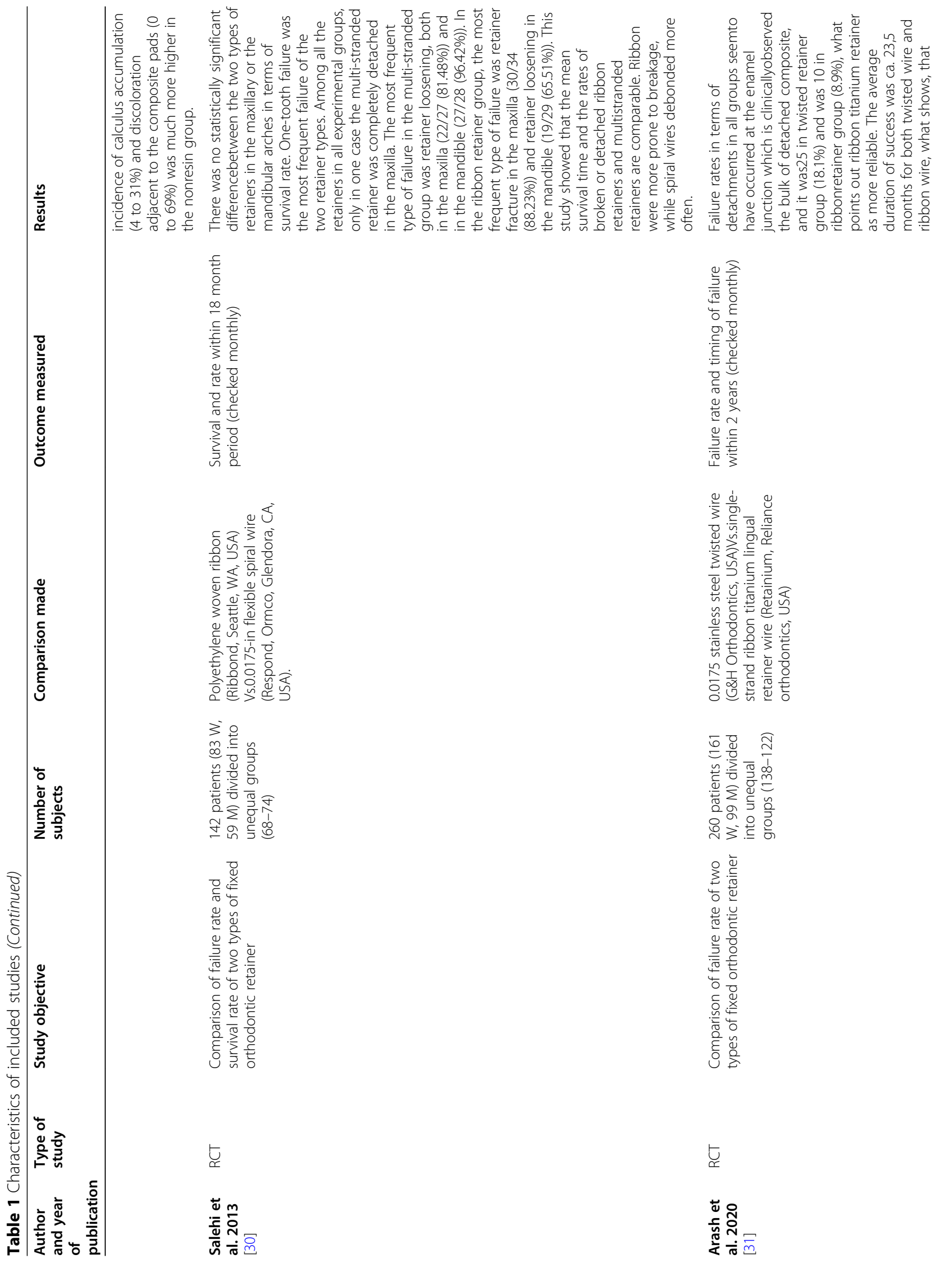




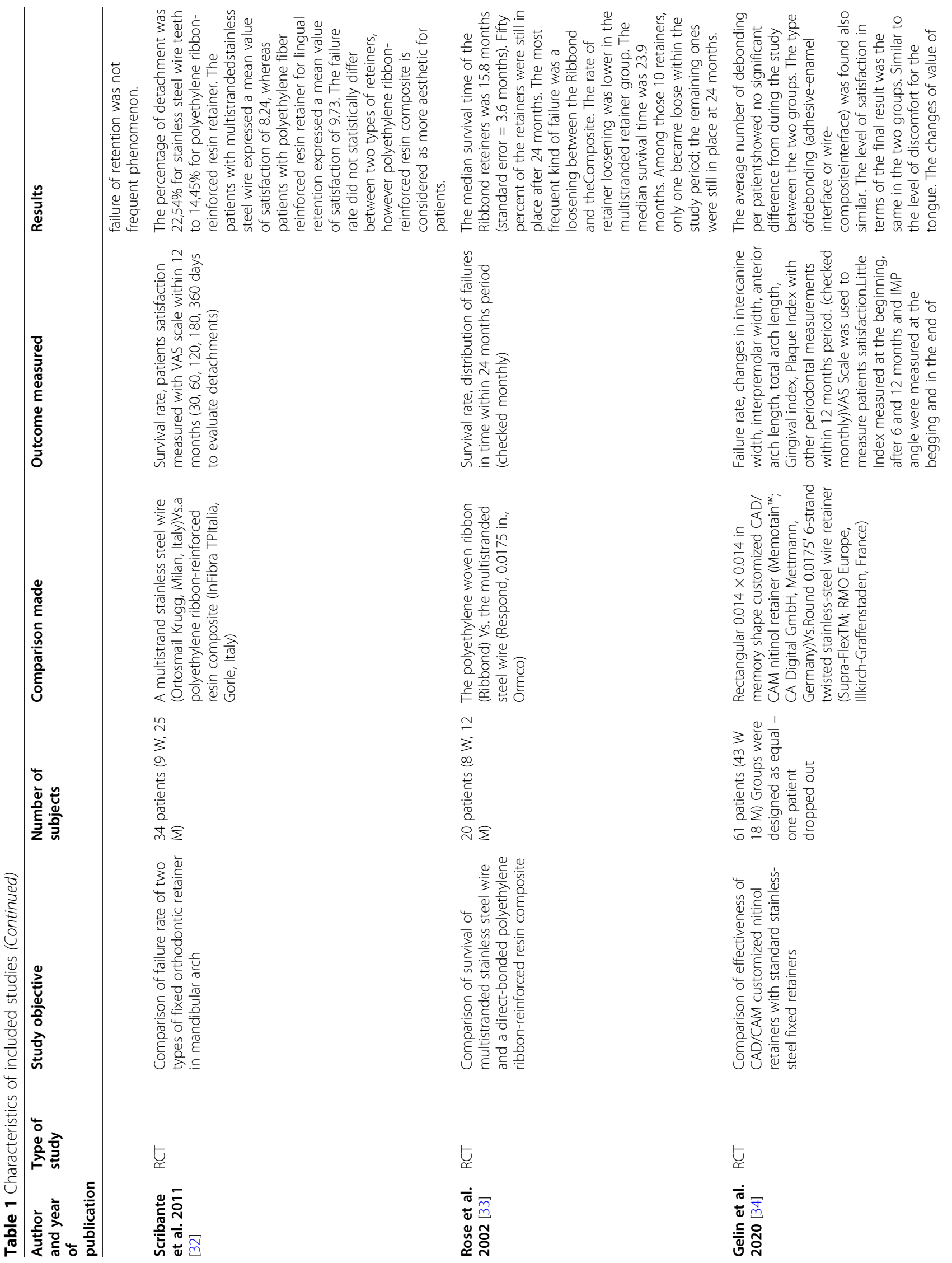




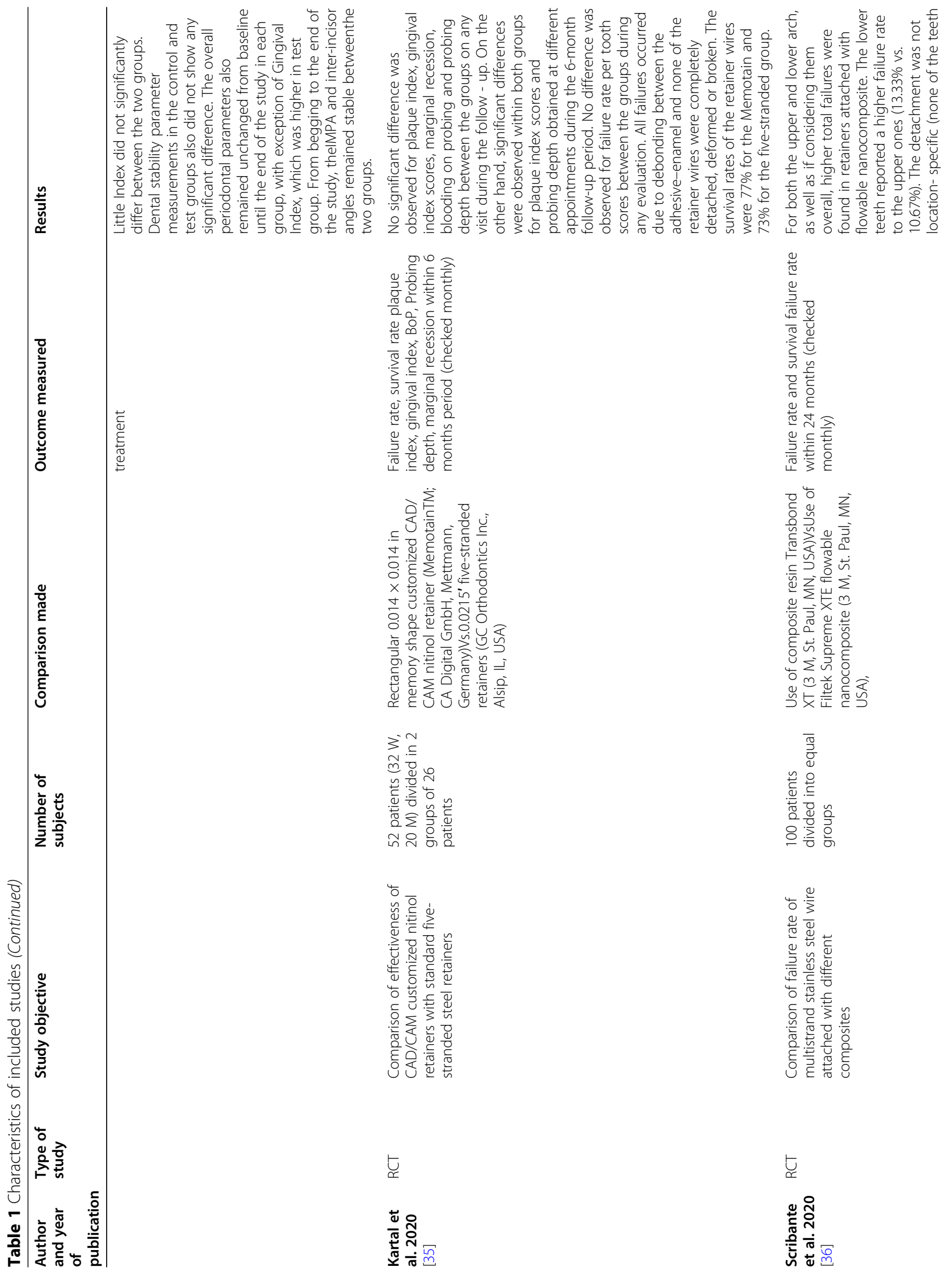




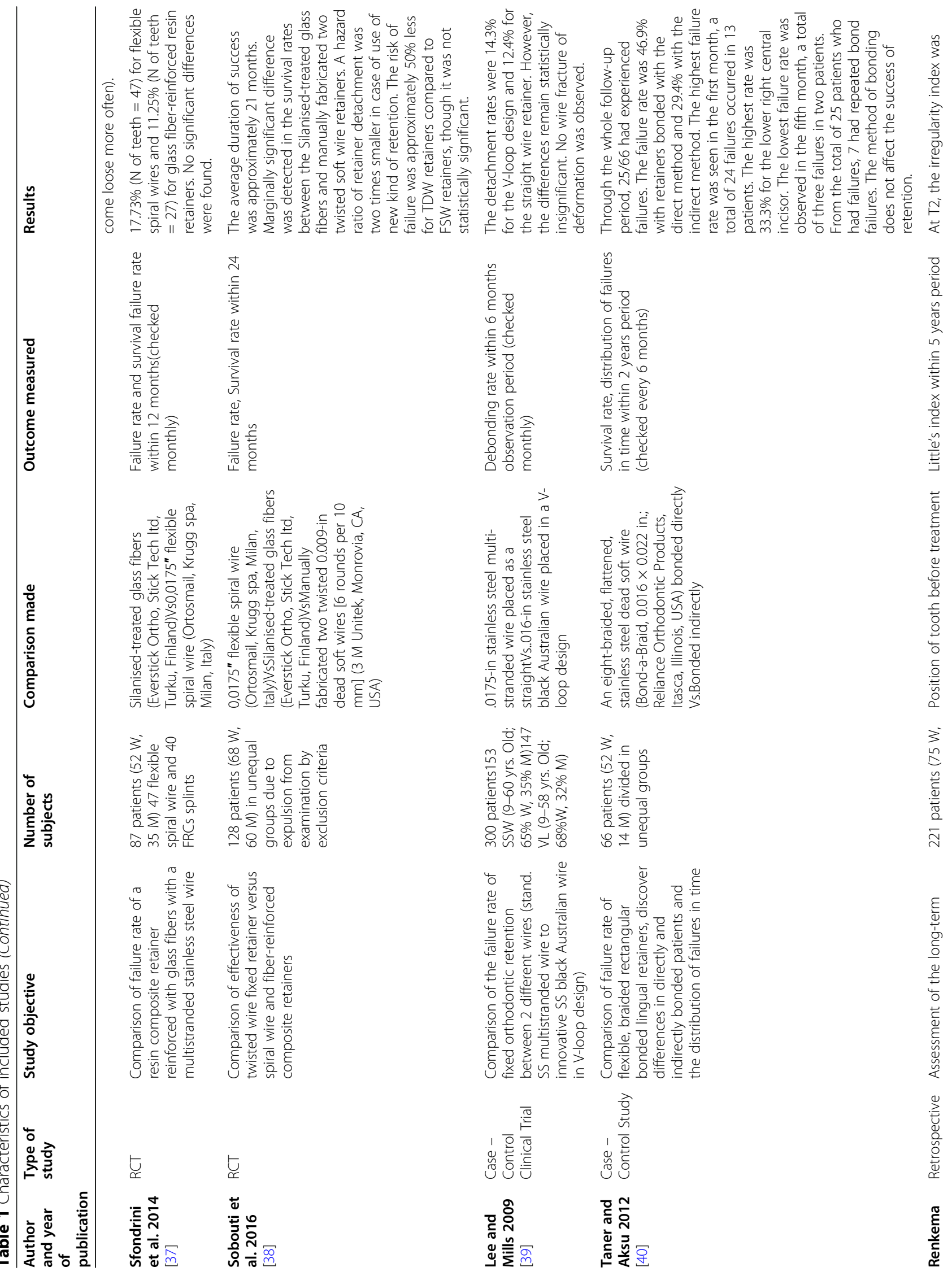




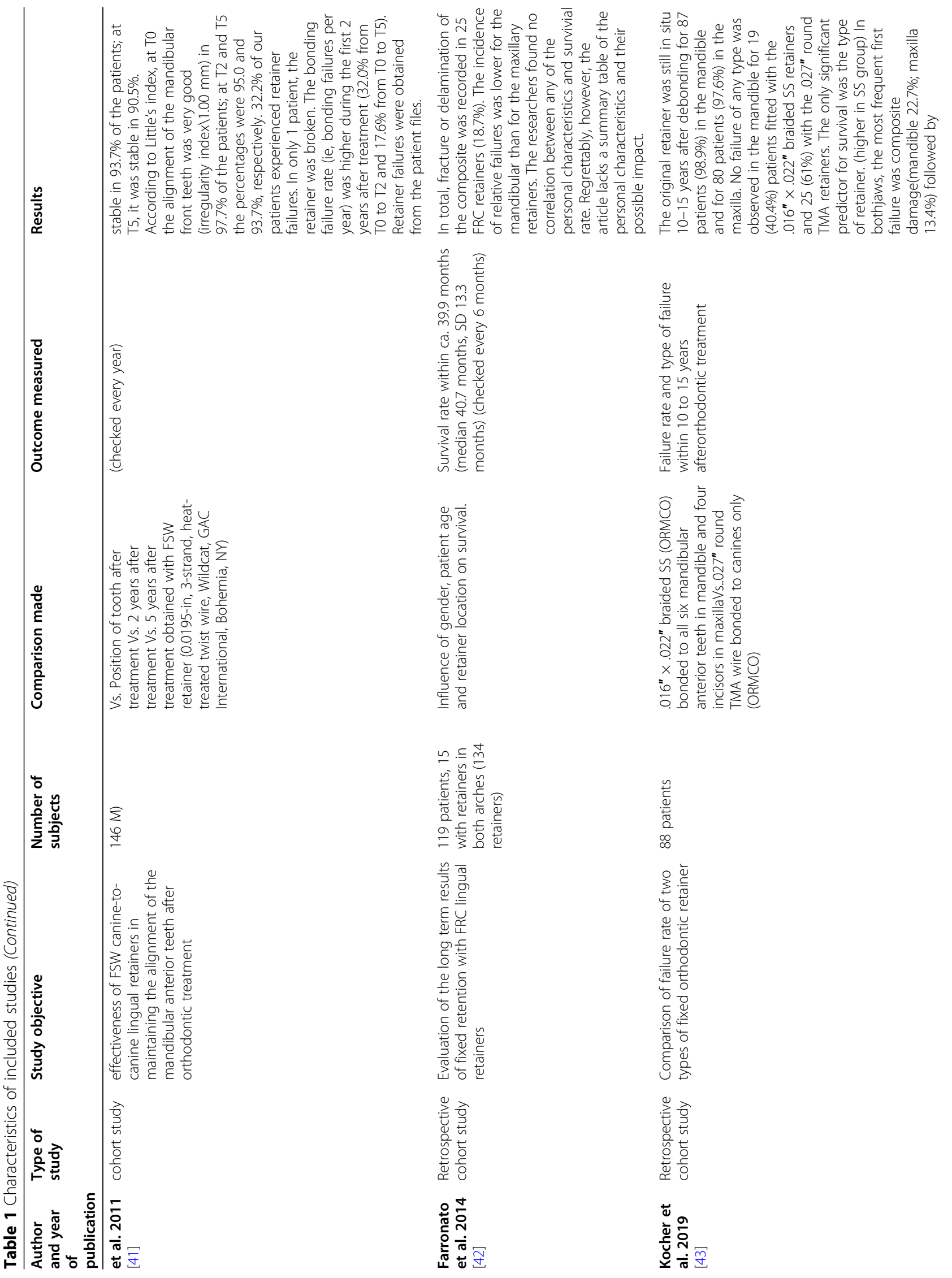




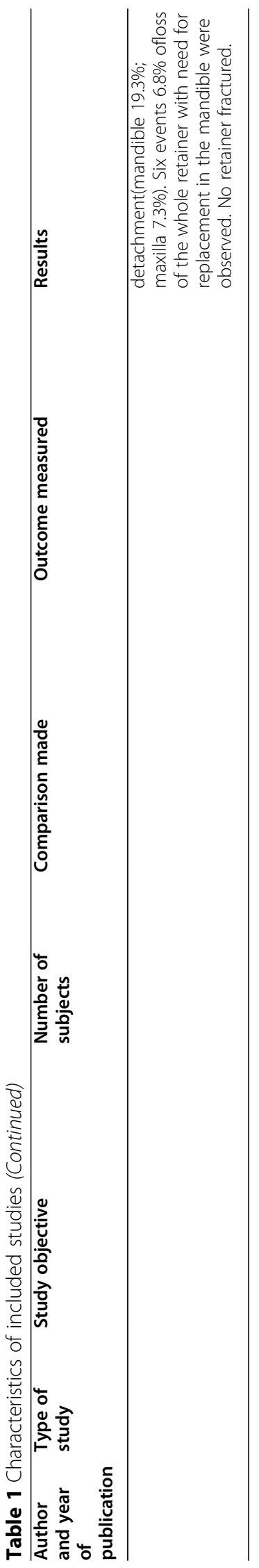



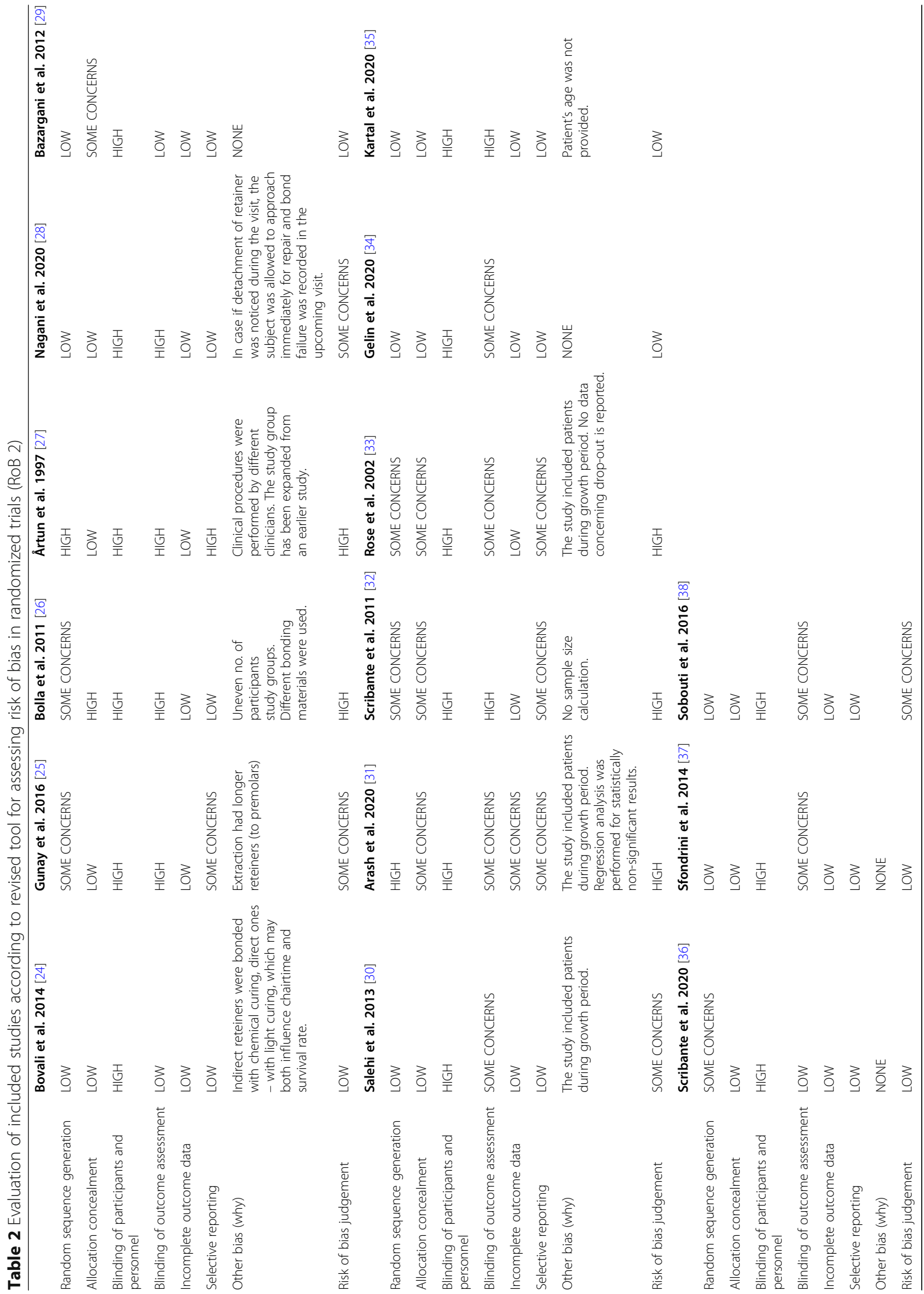
Table 3 Newcastle-Ottawa Quality Assessment Form for Case-control Studies

\begin{tabular}{|c|c|c|c|}
\hline Study & & Lee and Mills 2009 [39] & Taner and Aksu 2012 [40] \\
\hline \multirow[t]{4}{*}{ Selection } & $\begin{array}{l}\text { Is the case definition } \\
\text { adequate? }\end{array}$ & 1 & 1 \\
\hline & $\begin{array}{l}\text { Representativeness of the } \\
\text { cases }\end{array}$ & 0 - not described properly & 0 - not described properly \\
\hline & Selection of Controls & 1 & 1 \\
\hline & Definition of Controls & 1 & 1 \\
\hline \multirow[t]{2}{*}{ Comparability } & \multirow{2}{*}{$\begin{array}{l}\text { Comparability of cases } \\
\text { and controls on the basis } \\
\text { of the design or analysis }\end{array}$} & 1 & 2 \\
\hline & & $\begin{array}{l}\text { The procedures of retainer bonding and follow - } \\
\text { up were standardized. However, in some cases, not } \\
\text { strictly defined, the procedure was modified. The } \\
\text { number of teeth bonded to retainer differed in } \\
\text { induvial patients. }\end{array}$ & $\begin{array}{l}\text { The procedures of retainer bonding and follow - } \\
\text { up were standardized. The same wire, adhesive } \\
\text { and light curing unit were used in both groups. } \\
\text { However, the additional chemical adhesive was } \\
\text { used in indirect bonding group The patients were } \\
\text { randomly assigned to the groups. }\end{array}$ \\
\hline \multirow[t]{3}{*}{ Outcome } & $\begin{array}{l}\text { Ascertainment of } \\
\text { exposure }\end{array}$ & 1 & 1 \\
\hline & $\begin{array}{l}\text { Same method of } \\
\text { ascertainment for cases } \\
\text { and controls }\end{array}$ & 1 & 1 \\
\hline & Non-Response rate & 1 & 1 \\
\hline Total & & 7 & 8 \\
\hline
\end{tabular}

provides neither superior stability nor lesser gingival influence compared to classical twisted stainless-steel wire retainer [34, 35]. Referring to the bonding procedure: direct vs. indirect the only difference is shorter chairtime $[24,40]$.

\section{Meta-analysis}

Opinions on the superiority of retention with FRC (fiber reinforced composite) or multistranded SS wire are contradictory in the included studies. Therefore, it seems pertinent to carry out a meta-analysis of failure rates among the included studies that compare the retention efficiency of FRC and the 0.0175" stainless steel wire. There were 7 included studies in meta-analysis. Total sample size of all included studies is 503 patients and 516 reteiners. The data used to extracted and perform meta-analysis is shown in Table 5.

The results are shown on Fig. 2. Positive value of LRR indicates greater risk of FRC usage, negative - of MSS usage. Three studies showed very consistently the

Table 4 Newcastle-Ottawa Quality Assessment Form for Cohort Studies

\begin{tabular}{|c|c|c|c|c|}
\hline Study & & Renkema et al. 2011 [41] & Farronato et al. 2014 [42] & $\begin{array}{l}\text { Kocher et al. } 2019 \\
\text { [43] }\end{array}$ \\
\hline \multirow[t]{4}{*}{ Selection } & $\begin{array}{l}\text { Representativeness of the exposed } \\
\text { cohort }\end{array}$ & 1 & 0 - not properly described & 1 \\
\hline & $\begin{array}{l}\text { Selection of the non-exposed } \\
\text { cohort }\end{array}$ & 0 & 0 & 1 \\
\hline & Ascertainment of exposure & 1 & 1 & 1 \\
\hline & $\begin{array}{l}\text { Demonstration that outcome of } \\
\text { interest was not present at start of } \\
\text { study }\end{array}$ & 1 & 1 & 1 \\
\hline \multirow[t]{2}{*}{ Comparability } & \multirow{2}{*}{$\begin{array}{l}\text { Comparability of cohorts on the } \\
\text { basis of the design or analysis } \\
\text { controlled for confounders }\end{array}$} & 0 & 0 & 2 \\
\hline & & $\begin{array}{l}\text { There was only one cohort } \\
\text { group, which was evaluated } \\
\text { referring to different factors. }\end{array}$ & $\begin{array}{l}\text { There was only one cohort } \\
\text { group, which was evaluated } \\
\text { referring to different factors. }\end{array}$ & $\begin{array}{l}\text { The data collection } \\
\text { and clinical evaluation } \\
\text { were the same. }\end{array}$ \\
\hline \multirow[t]{3}{*}{ Outcome } & Assessment of outcome & 1 & 1 & 1 \\
\hline & $\begin{array}{l}\text { Was follow-up long enough for out- } \\
\text { comes to occur }\end{array}$ & 1 & 1 & 1 \\
\hline & Adequacy of follow-up of cohorts & 1 & 1 & 1 \\
\hline Total= & & 6 & 5 & 9 \\
\hline
\end{tabular}




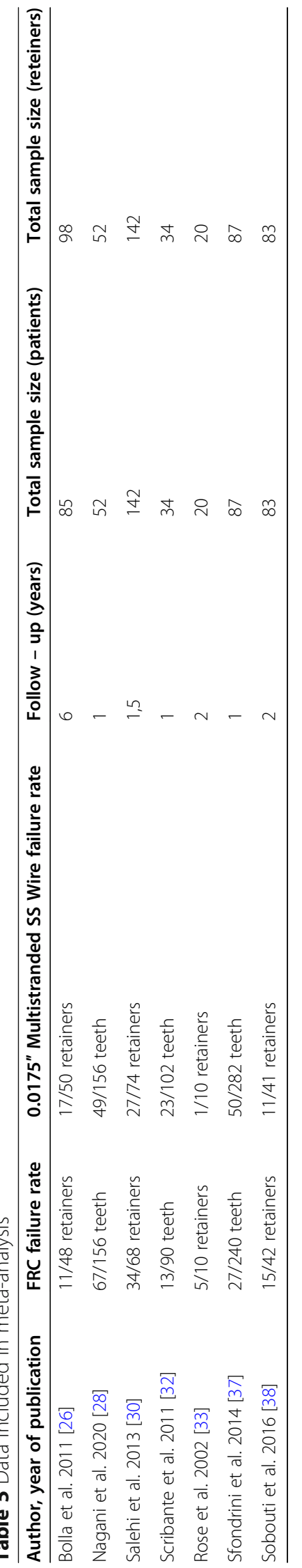




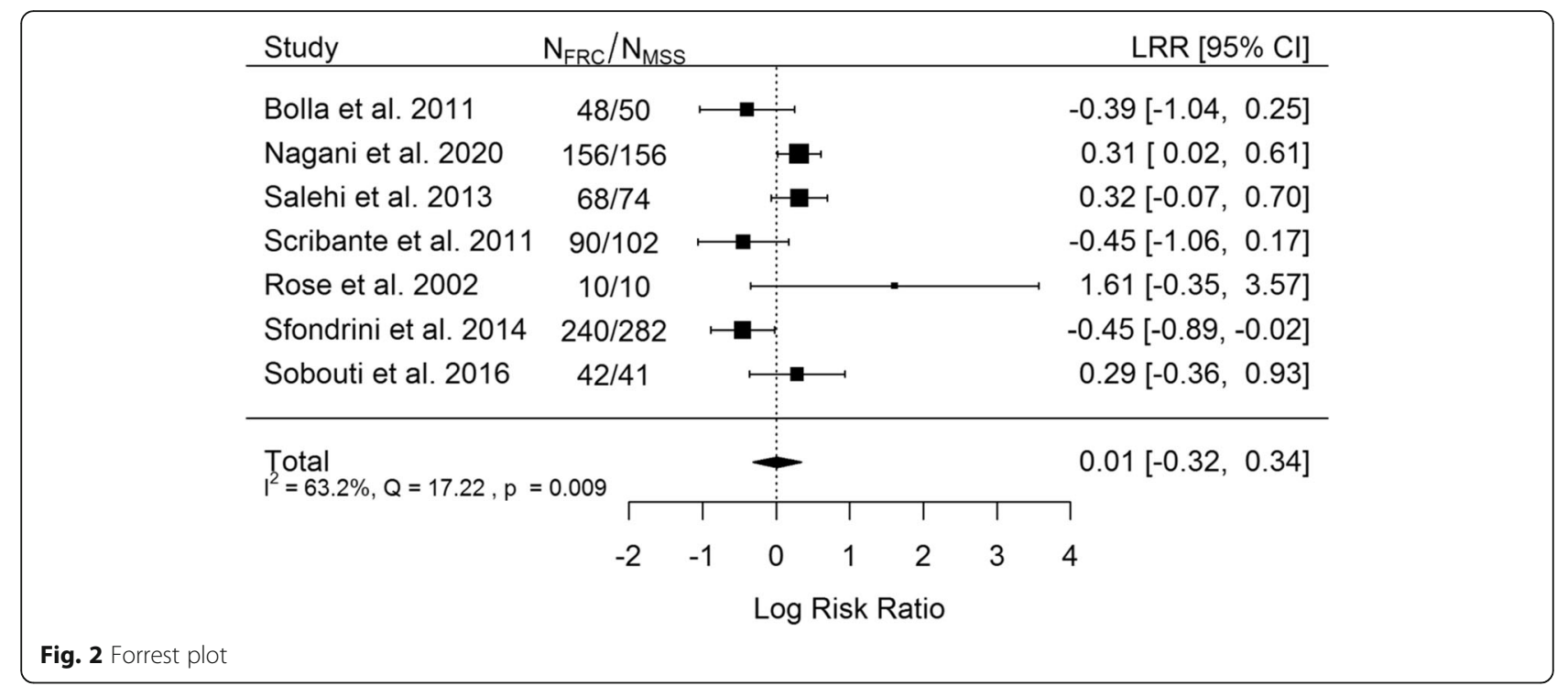

advantage of FRC and three - equally consistent with the advantage of multistranded steel wire. The study by Rose et al. reports results contradictory to all the other studies included in the meta-analysis. However, it does not have a large impact on the results of the meta-analysis, due to the small size of the studied sample. As it can be seen from the results of the calculations, there is no statistically significant difference between the type of material used and the possible risk of failure.

The higher the risk of FRC retention failure in the studies the higher the overall level of risk. (Fig. 3). This indicates that in the studies where failure occurred much more often than in the others, there was a much greater risk of retention failure while using FRC than while using SS wire. This indicates that FRC retention is definitely more sensitive to operator skills, and with incorrect technique of bonding, the possibility of failure events is much higher.

The type of wire used has an insignificant $(p=0.868)$ effect size. Results of the studies included are inconsistent - heterogeneity is significant $(p=0.009), 63.2 \%$ of the variability come from heterogeneity. Funnel plot (Fig. 4) does not reveal publication bias.

Due to the fact that the included studies differed in the units in which the failure rate is expressed (no. of detached reteiners and no. of detached teeth), it was examined whether there were significant differences between this group of studies.

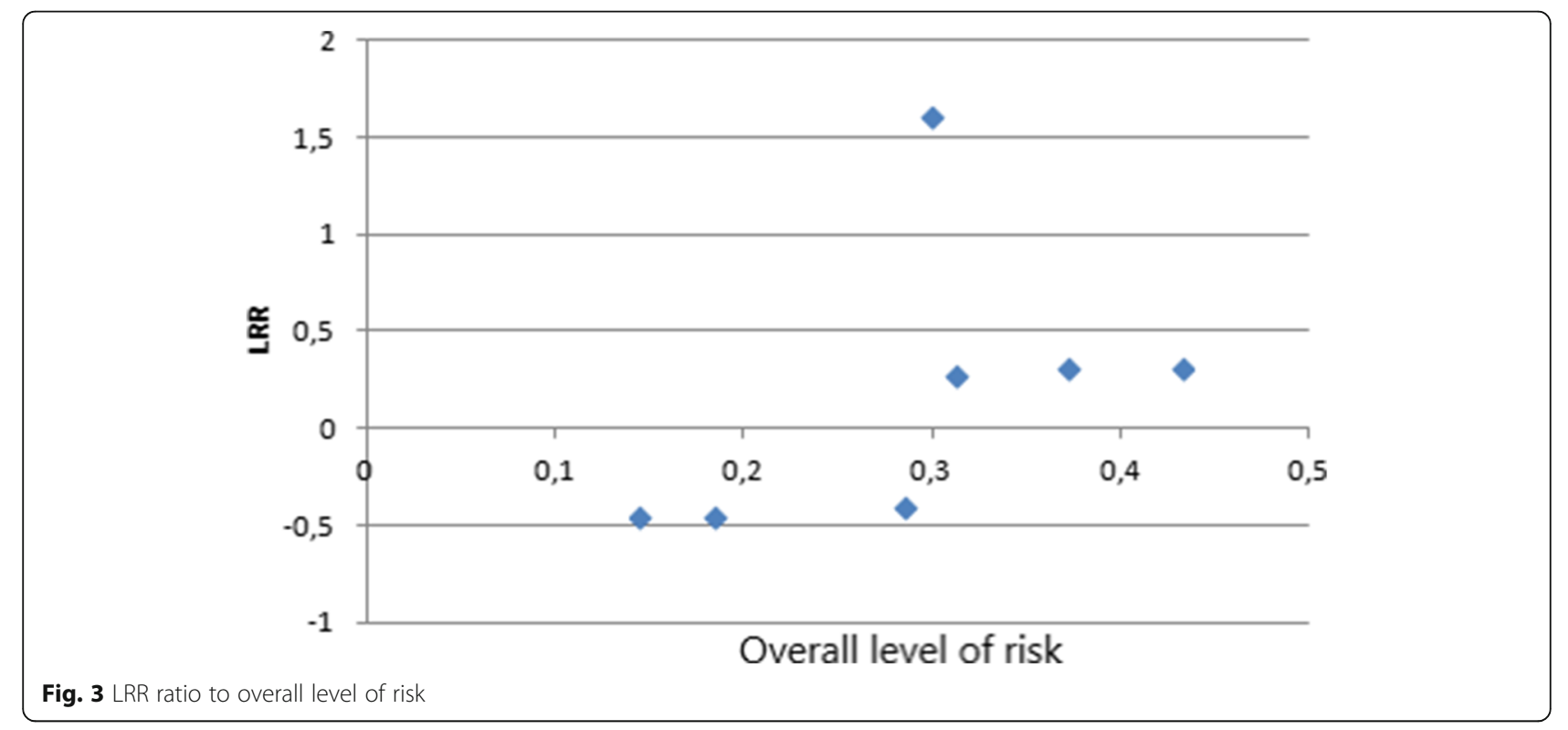




\section{Funnel plot}

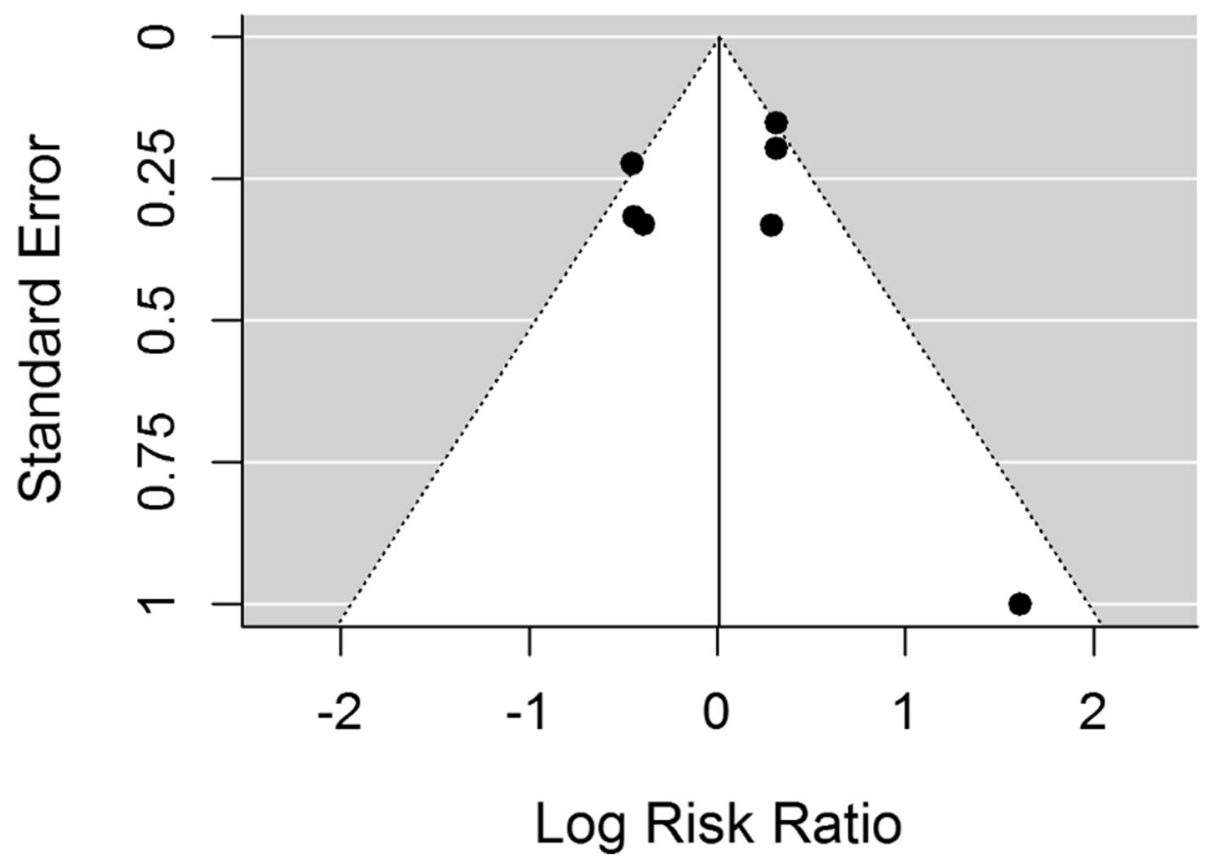

Fig. 4 Funnel plot

In the group of studies with failure rate counted by the number of detached individual teeth used wire has small insignificant negative effect size, while in the group of studies with failure rate counted by the number of detached retainers - small positive effect size. Study results were inconsistent in the first group - heterogeneity was significant $(p=0.005), 78.0 \%$ of the variability come from heterogeneity. However, despite the split, there were still no significant differences between the FRC and MSS groups. This means that the "unit of measure" of failure did not affect the overall conclusions coming from the meta-analysis (Fig. 5).

It seems also extremely interesting whether the followup time was not a factor that may differentiate the effectiveness of the compared types of retention. Therefore, it was concluded that it is worth sub-classifying the included studies into two groups - short-term (up to 12 months) and long-term follow-up (more than 12 months). The shortest follow-up in the included studies was 1 year. That is why 1 year has therefore become the dividing line between short-term and long-term research (Fig. 6).

However, also in this part of the study, there was no statistically significant difference between the two groups, which strongly confirms the statement made on collective meta-analysis. The studies included in the entire meta-analysis were highly heterogeneous, but it results from the specificity of the treatment in the retention phase - clinical approach was diverse in various studies.

\section{Discussion}

This systematic review aimed to set out the viable evidence on possible factors affecting the failure of fixed orthodontic retention, using both qualitative and quantitative synthesis.

The follow - up period in included RCTs ranged from 6 months in the study by Lee and Mills [39] to 24 months by Sobouti et al. 2016 [38] and in all of RCTs patients has been checked monthly. In cohort studies follow - up period lasted from 40 months to 15 years, while in case-control studies it ranged from 6 months to 2 years with different frequency of check-ups. It is worth mentioning, that the failures tend to occur mostly within 2 years after retainer placement, [41] mostly in the first 3 months period, $[24,33,40]$ or within first 6 months, when after this time occurred first check-up [42].

According to the literature, failure of a fixed retention may result from detachment between wire and composite, breaking the interface between adhesive and enamel, wire deformation or untwisting (round wires) [44] or wire fracture within approximal surface [45]. The critical 


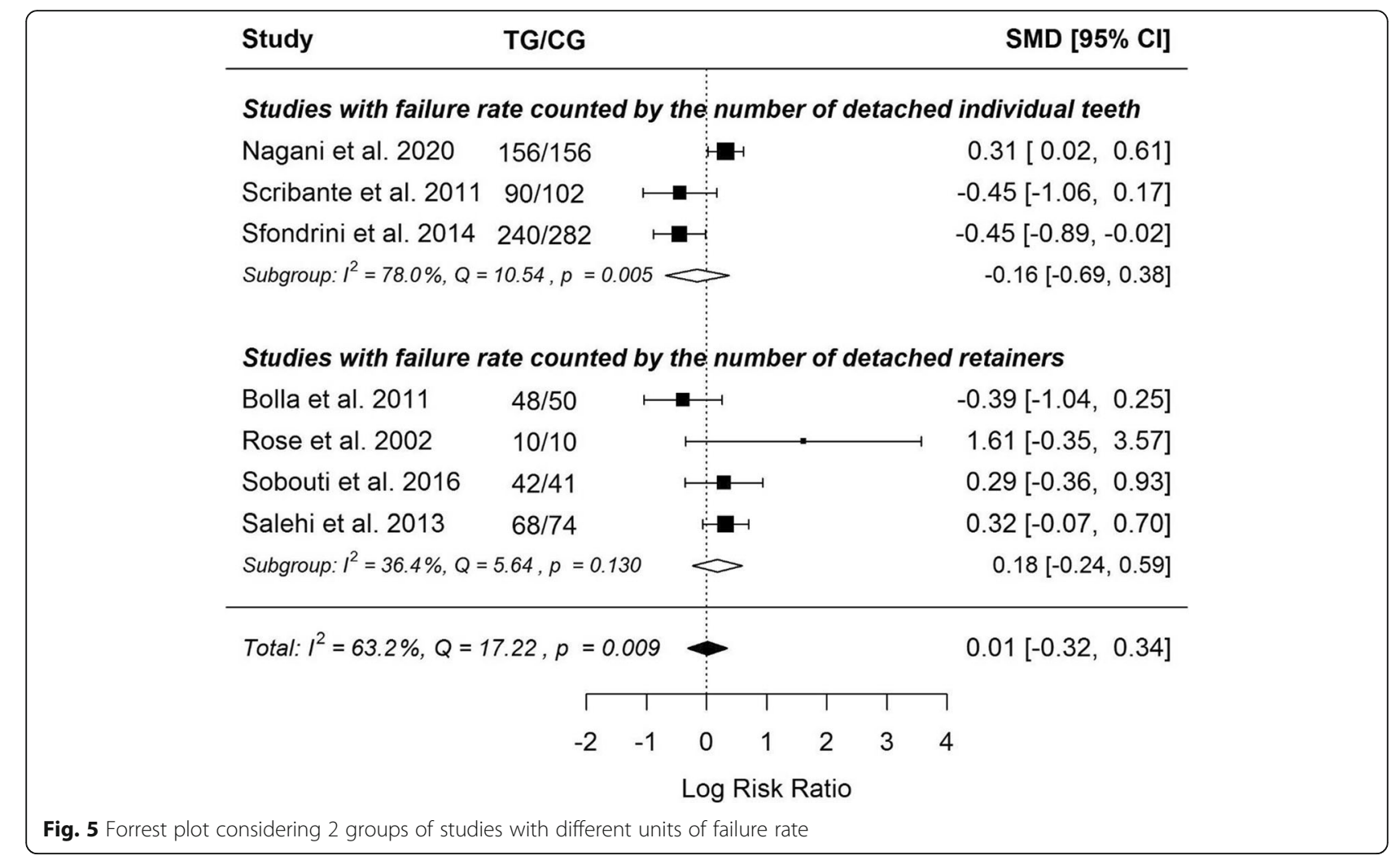

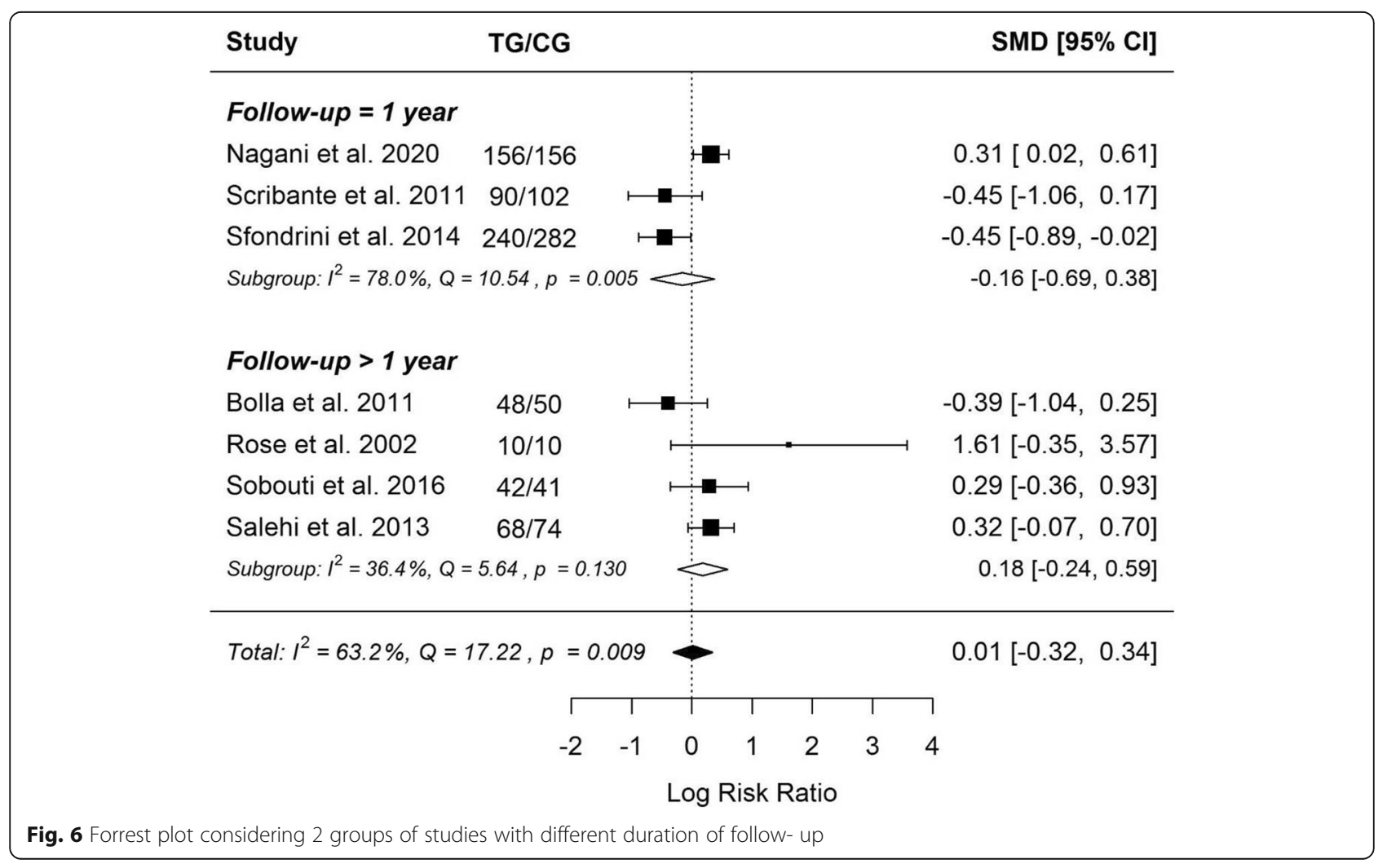


factors influencing a successful retainer bonding are: clean enamel surface to be bonded, dry field and avoiding occlusal interference [46]. The present study shows that breaking the interface between wire and composite or wire deformation are not prevalent causes of failures in fixed retention. The same refers to wire untwisting published in case reports [44, 47] and in-vitro studies $[48,49]-$ it did not occur in any of the studies meeting the inclusion criteria for a systematic review. On the other side, breaking the interface between composite and enamel is a very important cause for a failure. It is evident that maximum effort should thus be made to improve the bonding procedure. The present study confirmed the importance of the skills of the personnel to perform the bonding procedure. Moreover, the use of a bonding agent proved to improve bonding efficacy.

Concerning wire fracture, from the present study, it is a factor of failures, but not the one of the highest importance. Contrary conclusions refer to FRC which rather tends to break than to debond.

In the included studies, no clear effect of the wire used (SS wire, NiTi) on the patient's periodontal condition was found [27, 34, 35]. Either, in the literature, no detrimental effect of the presence of a retention wire on the health of periodontal tissues was found, indicating a greater risk of periodontitis in the fixed retention obtained with FRC [50-52]. Interestingly, the positioning of the retainer more coronally or gingivally should not affect the occurrence of symptoms of periodontal tissues, either [53]. The most important factor influencing the presence of plaque, calculus or inflammation is the patient's awareness and daily hygiene, that is, factors that would always present better in clinical trial conditions than in patients who do not undergo specific, frequent control [50]. Bonding to enamel proved to be critical for the success of permanent retention. It is obvious that bonding strength is influenced by the etching procedure $[54,55]$. In the studies included, etching times declared ranged from $15 \mathrm{~s}$ to $60 \mathrm{~s}$, the most prevalent time was 30s. Moreover, the concentrations of phosphoric acid were different, from 32 to $37 \%$. No detailed description of the rinsing time is provided in any of the studies included, most authors write that the etching agent was "rinsed thoroughly". Eventual effect of the etching or rinsing time on debonding rates could be a subject of future studies, that could improve the existing knowledge and allow to create clinical recommendations.

A phenomenon that most influences the risk of bias in randomized clinical trials is the nature of the process itself. It is impossible to perform blinding on the staff or on the patient. Both are aware of the bonding fixed retainer process taking place. In the case of studies verifying patient satisfaction, patient itself was able to distinguish the FRC or CAD / CAM retainer from the standard retainer due to its appearance or method of application. Most RCTs did not provide an objective evaluation of the clinical results of the applied solutions by a different investigator than the one who was not involved in the retention bonding, either. This could be a simple solution to implement, and certainly reducing the risk of bias. The vast majority of studies demonstrate no problems with introducing and describing the processes of randomization and allocation in patients selection for the study groups as well as in outcome data presentation. A possible risk of selective reporting was found in several studies [25, 27, 31-33]. However, it should be pointed out, that there were other risks of bias. The most prevalent were: the use of different bonding agents in different study groups (Bovali and Bolla) [24, 26] and including patients during growth (under 18th years of age). Growth affects the stability of retention, thus the number of young people in the distribution of the study group could have significantly influenced the results of the research. (Sobouti, Kartal, Rose, Salehi, Arash) [30, 31, 33, 35, 37]. Tooth movement resulting from ageing occurs in all subjects, disregarding the positive or negative history of orthodontic treatment. In most of the studies included in review of Schubert et al., young patients showed faster orthodontic movement in the first phase of treatment and more pronounced cytokine levels [56].

The clinical-control studies did not present high level of risk of the bias. However, in both cases, the criteria for including patients in the study were not adequately described $[39,40]$. Doubts arise on the representativeness of the study groups, and thus the adequacy of the study results to the general population. Lee and Millis sometimes altered the procedure of retainer bonding in an inaccurately defined number of patients, which could have an impact on their results [39].

The included cohort studies were at greatest risk of bias. In the studies of Renkema et al. [41] and Farronato et al., [42] there was only one cohort group, which was evaluated referring to different personal factors. Additionally, Farronato et al. [42] did not adequately provide inclusion criteria to the cohort. In contrast, the studies by Kocher et al. [43] were designed, conducted and described in a model way for this type of research. This systematic review has some limitations due to several factors. First of all, this study is limited by the heterogeneity of design between included studies, different types of wire used, different outcomes measured and elements on which some studies focused on. Many studies have also included developmental follow-up on patients. Growth inevitably has an impact on the outcome stability in the retention phase. Another limitation of this systematic review is the period of follow-up and different frequency of check-ups in the included studies. The vast 
majority of patients came for control visits every month. However, there are studies in which the retention status was tested every few months, 6 months or even every year. From the results of observations from monthly surveys, we are able to conclude that such a rare observation causes many processes in the oral cavity to be missed at the beginning of the retention phase. In metaanalysis, as failure rate, fractures and debonding were introduced together as failures. Breakage is caused by stiffness of the material and deboning is associated with its elasticity. Thus, both this type of failures are materialdepended, that is it seemed reasonable to put them in the one pool.

Thus, the available scientific evidence did not support a superior quality of any wire type or fiber splint, regarding failure rate or stability of the alignment. However, fiber splints break more often, whereas flexible spiral wires are more likely to debond [26, 30, 33, 43]. Round TMA (Titanium-Molybdenum alloy) .027" wire and braided SS (Stainless Steel) .016" × .022" did not tend to break within 15 years of follow-up. However, stainless steel wires were more prone to detach than TMA [43]. It has been proved, that patients consider fiber splint wires as more aesthetic and comfortable than flexible spiral SS wire [40]. Concerning the bonding procedure, it has been proved that indirect bonding is less chairtime consuming. As far as bonding materials are concerned, the use of bonding resin significantly reduces failure rate. A single study reported less failures with Transbond XT versus flowable Filtek Supreme XTE.

\section{Conclusions}

1. The follow-up periods in RCTs and in case-control studies ranged from 6 months to 2 years; in cohort studies - from 3 to 15 years.

2. No retainer is proved to guarantee a perfect stability of dental alignment.

3. The failure rate ranges from 7.3 to $50 \%$, mostly occurs in the first 3 to 6 months of retention, more frequently in the maxilla than in the mandible.

4. The retainer should be bonded to all the adherent teeth, preferably with the additional use of the bonding agent.

5. No wire or fiber splint present superior characteristics concerning failure rate.

6. In the first 6 months after retainer bonding the patient should be under frequent control of retention status.

7. Indirect retainer bonding is associated with a shorter chairtime.

8. FRC retention is definitely more sensitive to operator skills, and with imperfect technique of bonding, the possibility of failure is much higher

\section{Abbreviations}

SS: Stainless steel; TMA: Titanium-Molybdenum Alloy; FRC: Fiber reinforced composite; RCT: Randomized clinical trial; RCCT: Randomized controlled clinical trial; CCS: Case-control study; CAD/CAM: Computer-aided design/ computer-aided manufacture; LRR: Log Risk Ratio

\section{Supplementary Information}

The online version contains supplementary material available at https://doi. org/10.1186/s13005-021-00281-3.

\section{Additional file 1.}

Additional file 2 .

Acknowledgements

Not applicable.

\section{Authors' contributions}

Conceptualization, M.J.; methodology, M.J.; validation, J.JO., K.G. and M.M..; formal analysis, M.M.; investigation, M.J.; data curation, M.M.; writing—original draft preparation, M.J., J.JO; writing—review and editing K.G..; visualization, M.J.; supervision, J.JO.; project administration, M.J. and J.JO. All authors have read and agreed to the published version of the manuscript.

\section{Funding}

This study did not receive any external funding.

Availability of data and materials

Not applicable.

\section{Declarations}

Ethics approval and consent to participate

Not applicable.

Consent for publication

Not applicable.

\section{Competing interests}

The authors declare that they have no competing interests.

\section{Author details}

'Department of Interdisciplinary Dentistry, Pomeranian Medical University in Szczecin, 70-111 Szczecin, Poland. 'Department of Dental and Maxillofacial

Sciences, Sapienza University of Rome, 00161 Rome, Italy.

Received: 17 March 2021 Accepted: 5 July 2021

Published online: 24 July 2021

\section{References}

1. Bearn DR. Bonded orthodontic retainers: a review. Am J Orthod Dentofac Orthop. 1995:108(2):207-13. https://doi.org/10.1016/S0889-5406(95)70085-4.

2. Meade MJ, Millett D. Retention protocols and use of vacuum-formed retainers among specialist orthodontists. J Orthod. 2013;40(4):318-25. https://doi.org/10.1179/1465313313Y.0000000066.

3. Johnston CD, Littlewood SJ. Retention in orthodontics. Br Dent J. 2015: 218(3):119-22. https://doi.org/10.1038/sj.bdj.2015.47.

4. Bondemark L, Holm AK, Hansen K, Axelsson S, Mohlin B, Brattstrom V, et al. Long-term stability of orthodontic treatment and patient satisfaction. A systematic review. Angle Orthod. 2007;77(1):181-91. https://doi.org/10.2319/ 011006-16R.1.

5. Little RM, Riedel RA, Artun J. An evaluation of changes in mandibular anterior alignment from 10 to 20 years postretention. Am J Orthod Dentofac Orthop. 1988;93(5):423-8. https://doi.org/10.1016/0889-54 06(88)90102-3.

6. Andriekute A, Vasiliauskas A, Sidlauskas A. A survey of protocols and trends in orthodontic retention. Prog Orthod. 2017:18(1):31. https://doi.org/10.11 86/s40510-017-0185-x. 
7. Lai CS, Grossen JM, Renkema AM, Bronkhorst E, Fudalej PS, Katsaros C. Orthodontic retention procedures in Switzerland. Swiss Dent J. 2014;124(6): 655-61

8. Birkeland K, Bøe OE, Wisth PJ. Relationship between occlusion and satisfaction with dental appearance in orthodontically treated and untreated groups. A longitudinal study. Eur J Orthod. 2000;22(5):509-18. https://doi.org/10.1093/ejo/22.5.509.

9. Albino JE, Lawrence SD, Tedesco LA. Psychological andsocial effects of orthodontic treatment. J Behav Med. 1994;17(1):81-98. https://doi.org/10.1 007/BF01856884.

10. Valiathan M, Hughes E. Results of a survey-based study to identify common retention practices in the United States. Am J Orthod Dentofac Orthop. 2010; 137(2):170-7; discussion 177. https://doi.org/10.1016/j.ajodo.2008.03.023.

11. Littlewood SJ. British orthodontic society. BOS response to article on 'Hold that smile' campaign. Br Dent J. 2018;224(12):925-6. https://doi.org/10.1038/ sj.bdj.2018.439.

12. Page MJ, McKenzie JE, Bossuyt PM, Boutron I, Hoffmann TC, Mulrow CD, et al. The PRISMA 2020 statement: an updated guideline for reporting systematic reviews. BMJ. 2021;372:n71. https://doi.org/10.1136/bmj.n71

13. Beller EM, Glasziou PP, Altman DG, Hopewell S, Bastian H, Chalmers I, et al. PRISMA for abstracts: reporting systematic reviews in journal and conference abstracts. PLoS Med. 2013;10(4):e1001419. https://doi.org/10.13 71/journal.pmed.1001419.

14. Rethlefsen ML, Kirtley S, Waffenschmidt S, et al. PRISMA-S: an extension to the PRISMA statement for reporting literature searches in systematic reviews. Syst Rev. 2021;10(1):39. Published 2021 Jan 26. https://doi.org/10.11 86/s13643-020-01542-z.

15. Higgins JPT, Thomas J, Chandler J, Cumpston M, Li T, Page MJ, et al., editors. Cochrane handbook for systematic reviews of interventions. 2nd ed. Chichester: Wiley; 2019. https://doi.org/10.1002/9781119536604.

16. Sackett DL, Strauss SE, Richardson WS, Rosenberg W, Haynes BR. Evidencebased medicine: how to practice and teach EBM. 2nd ed. Philadelphia: Elsevier Churchill Livingstone; 2000

17. Sterne JAC, Savović J, Page MJ, Elbers RG, Blencowe NS, Boutron I, et al. RoB 2: a revised tool for assessing risk of bias in randomised trials. BMJ. 2019;366: |4898. https://doi.org/10.1136/bmj.|4898.

18. Higgins JPT, Savović J, Page MJ, Elbers RG, Sterne JAC. Assessing risk of bias in a randomized trial. In: Cochrane Handbook for Systematic Reviews of Interventions: John Wiley \& Sons, Ltd; 2019. p. 205-28. https://doi.org/10.1 002/9781119536604.ch8

19. Wells G, Shea B, O'Connell D, Peterson JE, Welch V. The Newcastle-Ottawa scale (NOS) for assessing the quality of case-control studies in metaanalyses. Eur J Epidemiol. 2011;25:603-5.

20. Wells GA, Brodsky L, O'Connell D, et al. An evaluation of the Newcastle Ottawa Scale: an assessment tool for evaluating the quality of nonrandomized studies. In: XI International Cochrane Colloquium: Evidence, Health Care and Culture. Book of Abstracts. XI Cochrane Colloquium Barcelona; 2003:26.

21. Del Re AC. A practical tutorial on conducting meta-analysis in R. Quant Methods Psychol. 2015;11(1):37-50.

22. Borenstein, M., Hedges, L.V., Higgins, J.P.T. and Rothstein, H.R. (2009). Effect sizes based on binary data ( $2 \times 2$ tables). In introduction to meta-analysis (eds M. Borenstein, L.V. Hedges, J.P.T. Higgins and H.R. Rothstein). doi: https://doi.org/10.1002/9780470743386.ch5.

23. Higgins JPT, Thompson SG. Quantifying heterogeneity in a meta-analysis. Stat Med. 2002;21(11):1539-58. https://doi.org/10.1002/sim.1186.

24. Bovali $\mathrm{E}$, Kiliaridis $\mathrm{S}$, Cornelis MA. Indirect vs direct bonding of mandibular fixed retainers in orthodontic patients: a single-center randomized controlled trial comparing placement time and failure over a 6-month period. Am J Orthod Dentofac Orthop. 2014;146(6):701-8. https://doi.org/1 0.1016/j.ajodo.2014.08.015.

25. Gunay $\mathrm{F}, \mathrm{Oz}$ AA. Clinical effectiveness of 2 orthodontic retainer wires on mandibular arch retention. Am J Orthod Dentofac Orthop. 2018;153(2):2328. https://doi.org/10.1016/j.ajodo.2017.06.019.

26. Bolla E, Cozzani M, Doldo T, Fontana M. Failure evaluation after a 6-year retention period: a comparison between glass fiber-reinforced (GFR) and multistranded bonded retainers. Int Orthod. 2012;10(1):16-28. English, French. doi: https://doi.org/10.1016/j.ortho.2011.12.005.

27. Artun J, Spadafora AT, Shapiro PA. A 3-year follow-up study of various types of orthodontic canine-to-canine retainers. Eur J Orthod. 1997 Oct;19(5):5019. https://doi.org/10.1093/ejo/19.5.501.
28. Nagani NI, Ahmed I, Tanveer F, Khursheed HM, Farooqui WA. Clinical comparison of bond failure rate between two types of mandibular caninecanine bonded orthodontic retainers- a randomized clinical trial. BMC Oral Health. 2020;20(1):180. https://doi.org/10.1186/s12903-020-01167-7.

29. Bazargani F, Jacobson S, Lennartsson B. A comparative evaluation of lingual retainer failure bonded with or without liquid resin. Angle Orthod. 2012; 82(1):84-7. https://doi.org/10.2319/032811-222.1.

30. Salehi P, Zarif Najafi H, Roeinpeikar SM. Comparison of survival time between two types of orthodontic fixed retainer: a prospective randomized clinical trial. Prog Orthod. 2013;14(1):25. https://doi.org/10.1186/2196-1 042-14-25.

31. Arash V, Teimoorian M, Farajzadeh Jalali Y, Sheikhzadeh S. Clinical comparison between multi-stranded wires and single strand ribbon wires used for lingual fixed retainers. Prog Orthod. 2020;21(1):22. https://doi.org/1 0.1186/s40510-020-00315-7.

32. Scribante A, Sfondrini MF, Broggini S, D'Allocco M, Gandini P. Efficacy of esthetic retainers: clinical comparison between multistranded wires and direct-bond glass Fiber-reinforced composite splints. Int J Dent. 2011;2011: 548356-5. https://doi.org/10.1155/2011/548356.

33. Rose E, Frucht $\mathrm{S}$, Jonas IE. Clinical comparison of a multistranded wire and a direct-bonded polyethylene ribbon-reinforced resin composite used for lingual retention. Quintessence Int. 2002;33(8):579-83.

34. Gelin E, Seidel L, Bruwier A, Albert A, Charavet C. Innovative customized CAD/CAM nickel-titanium lingual retainer versus standard stainless-steel lingual retainer: a randomized controlled trial. Korean J Orthod. 2020;50(6): 373-82. https://doi.org/10.4041/kjod.2020.50.6.373.

35. Kartal Y, Kaya B, Polat-Özsoy Ö. Comparative evaluation of periodontal effects and survival rates of Memotain and five-stranded bonded retainers : a prospective short-term study. J Orofac Orthop. 2021:82(1):32-41. English. https://doi.org/10.1007/s00056-020-00243-5.

36. Scribante A, Gallo S, Turcato B, Trovati F, Gandini P, Sfondrini MF. Fear of the relapse: effect of composite type on adhesion efficacy of upper and lower orthodontic fixed retainers: in vitro investigation and randomized clinical trial. Polymers (Basel). 2020;12(4):963. https://doi.org/10.3390/polym12040963.

37. Sfondrini MF, Fraticelli D, Castellazzi L, Scribante A, Gandini P. Clinical evaluation of bond failures and survival between mandibular canine-tocanine retainers made of flexible spiral wire and fiber-reinforced composite. J Clin Exp Dent. 2014 Apr 1;6(2):e145-9. https://doi.org/1 $0.4317 /$ jced.51379.

38. Sobouti F, Rakhshan V, Saravi MG, Zamanian A, Shariati M. Two-year survival analysis of twisted wire fixed retainer versus spiral wire and fiber-reinforced composite retainers: a preliminary explorative single-blind randomized clinical trial. Korean J Orthod. 2016;46(2):104-10. https://doi.org/10.4041/ kjod.2016.46.2.104

39. Lee KD, Mills CM. Bond failure rates for V-loop vs straight wire lingual retainers. Am J Orthod Dentofac Orthop. 2009;135(4):502-6. https://doi. org/10.1016/j.ajodo.2007.04.037

40. Taner T, Aksu M. A prospective clinical evaluation of mandibular lingual retainer survival. Eur J Orthod. 2012 Aug;34(4):470-4. https://doi.org/10.1093/ejo/cjr038.

41. Renkema AM, Renkema A, Bronkhorst E, Katsaros C. Long-term effectiveness of canine-to-canine bonded flexible spiral wire lingual retainers. Am J Orthod Dentofac Orthop. 2011;139(5):614-21. https://doi.org/10.1016/j.a jodo.2009.06.041.

42. Farronato D, Briguglio R, Mangano F, Azzi L, Grossi GB, Briguglio F. Survival of post-treatment canine-to-canine lingual retainers with fiber-reinforced composite resin: a retrospective study. Ann Stomatol (Roma). 2014;5(3):81-6.

43. Kocher KE, Gebistorf MC, Pandis N, Fudalej PS, Katsaros C. Survival of maxillary and mandibular bonded retainers 10 to 15 years after orthodontic treatment: a retrospective observational study. Prog Orthod. 2019;20(1):28. https://doi.org/10.1186/s40510-019-0279-8.

44. Shaughnessy TG, Proffit WR, Samara SA. Inadvertent tooth movement with fixed lingual retainers. Am J Orthod Dentofac Orthop. 2016;149(2):277-86. https://doi.org/10.1016/j.ajodo.2015.10.015.

45. Radlanski RJ, Zain ND. Stability of the bonded lingual wire retainer-a study of the initial bond strength. J Orofac Orthop. 2004;65(4):321-35. https://doi. org/10.1007/s00056-004-0401-4.

46. Butler J, Dowling P. Orthodontic bonded retainers. J Ir Dent Assoc. 2005;51: 29-32.

47. Pazera P, Fudalej P, Katsaros C. Severe complication of a bonded mandibular lingual retainer. Am J Orthod Dentofac Orthop. 2012;142(3):4069. https://doi.org/10.1016/j.ajodo.2012.01.019. 
48. Arnold DT, Dalstra M, Verna C. Torque resistance of different stainless steel wires commonly used for fixed retainers in orthodontics. J Orthod. 2016; 43(2):121-9. https://doi.org/10.1080/14653125.2016.1155814.

49. Sifakakis I, Pandis N, Eliades T, Makou M, Katsaros C, Bourauel C. In-vitro assessment of the forces generated by lingual fixed retainers. Am J Orthod Dentofac Orthop. 2011;139(1):44-8. https://doi.org/10.1016/j.ajodo.2010.02. 029 .

50. Arn ML, Dritsas K, Pandis N, Kloukos D. The effects of fixed orthodontic retainers on periodontal health: a systematic review. Am J Orthod Dentofacial Orthop. 2020;157(2):156-164.e17. https://doi.org/10.1016/j.a jodo.2019.10.010.

51. Juloski J, Glisic B, Vandevska-Radunovic V. Long-term influenceoffixed lingual retainers on the development of gingival recession:a retrospective, longitudinal cohort study. Angle Orthod. 2017;87(5):658-64. https://doi.org/1 $0.2319 / 012217-58.1$

52. Torkan S, Oshagh M, Khojastepour L, Shahidi S, Heidari S. Clinical and radiographic comparison of the effects of two types of fixed retainers on periodontium —a randomized clinical trial. Prog Orthod. 2014;15(1):47. https://doi.org/10.1186/s40510-014-0047-8.

53. Levin L, Samorodnitzky-Naveh GR, Machtei EE. The association of orthodontic treatment and fixed retainers with gingival health. J Periodontol. 2008;79(1 1):2087-92. https://doi.org/10.1902/jop.2008.080128.

54. Pouyanfar H, Tabaii ES, Aghazadeh S, Nobari SPTN, Imani MM. Microtensile bond strength of composite to enamel using universal adhesive with/ without acid etching compared to etch and rinse and self-etch bonding agents. Open Access Maced J Med Sci. 2018;6(11):2186-92. Published 2018 Nov 22. https://doi.org/10.3889/oamjms.2018.427.

55. El Gedaily M, Attin T, Wiedemeier DB, Tauböck TT. Impact of different etching strategies on margin integrity of conservative composite restorations in demineralized enamel. Materials (Basel). 2020;13(20):4500. Published 2020 Oct 11. https://doi.org/10.3390/ma13204500.

56. Schubert A, Jäger F, Maltha JC, Bartzela TN. Age effect on orthodontic tooth movement rate and the composition of gingival crevicular fluid : a literature review. J Orofac Orthop. 2020;81(2):113-25. English. https://doi.org/10.1007/ s00056-019-00206-5.

\section{Publisher's Note}

Springer Nature remains neutral with regard to jurisdictional claims in published maps and institutional affiliations.

Ready to submit your research? Choose BMC and benefit from:

- fast, convenient online submission

- thorough peer review by experienced researchers in your field

- rapid publication on acceptance

- support for research data, including large and complex data types

- gold Open Access which fosters wider collaboration and increased citations

- maximum visibility for your research: over $100 \mathrm{M}$ website views per year

At $\mathrm{BMC}$, research is always in progress.

Learn more biomedcentral.com/submissions 